\title{
Surface Treatment for GaN Substrate - Comparison of Chemical Mechanical Polishing and Inductively Coupled Plasma Dry Etching-
}

\author{
Hideo Aida*, Hidetoshi Takeda, Natsuko Aota, \\ Seong-Woo Kim and Koji Koyama \\ NJC Institute of Technology, Namiki Precision Jewel Co., Ltd., Adachi, Tokyo 123-8511, Japan
}

(Received August 6, 2012; accepted September 19, 2012)

Key words: GaN substrate, CMP, ICP dry etching, subsurface damage, plasma-induced damage

A direct comparison of surface treatment methods for $\mathrm{GaN}$ substrates, namely, chemical mechanical polishing (CMP) with a colloidal silica slurry and inductively coupled plasma (ICP) dry etching with $\mathrm{SiCl}_{4}$ gas, is presented, and their advantages and disadvantages are summarized. The subsurface damage is evaluated from the intensity of the cathodoluminescence (CL) emission spectrum and by CL imaging. Although the CMP-finished GaN substrate exhibits a perfect surface free of scratches and subsurface damage, the removal rate achieved is insufficiently high. On the other hand, ICP dry etching is seen to be able to remove only subsurface damage with a remarkably high removal rate but not remove the scratches induced by the mechanical process. In addition, the introduction of plasma-induced damage during ICP dry etching is suggested. Clear evidence of the introduction of plasma-induced damage, which is a network of point defects originating from the mechanical effects of dry etching such as ion bombardment, is shown in this study by demonstrating the ICP dry etching for a CMP-finished GaN substrate and by discussing the reasons for the degradation in CL intensity. On the basis of the experimental results, the current issues to be solved for CMP as well as ICP dry etching are summarized toward the development of a suitable surface treatment for GaN substrate for III-nitride epitaxy.

\section{Introduction}

Single-crystal bulk GaN substrates are one of the most promising candidates to replace sapphire substrates, which are commonly used for III-nitride devices such as light-emitting diodes (LEDs) and laser diodes (LDs), and to improve III-nitride device performance markedly by enabling homoepitaxial growth of III-nitride device films. Single crystals of bulk GaN can be grown by high-pressure solution growth (HPGS), ${ }^{(1)}$

${ }^{*}$ Corresponding author: e-mail: aida@namikipj.com 
hydride vapor phase epitaxy (HVPE), ${ }^{(2,3)}$ ammonothermal growth, ${ }^{(4)}$ and liquid phase epitaxy (LPE). ${ }^{(5)}$ After the growth of bulk crystals, the crystal undergoes a wafering process, including cutting, grinding, mechanical polishing, and chemical mechanical polishing (CMP). The surface produced by mechanical processes has a dense network of scratches and damage. However, to obtain high-performance thin-film devices on GaN substrate by homoepitaxy, it is essential to achieve a surface free of scratches and damage for the GaN substrate. Therefore, the final step of the wafering process, CMP, plays an extremely important role in the quality of subsequent homoepitaxial GaN films and related devices. ${ }^{(6)}$

Recently, we have reported for the first time a perfect surface of $\mathrm{GaN}$ free of scratches and subsurface damage by CMP with a colloidal silica slurry, which is the only report to the best of our knowledge dealing with the complete CMP for the GaN substrate. ${ }^{(7)}$ In the report, we confirmed the feasibility of CMP for the GaN substrate as the surface treatment for producing the surface with a complete absence of damage and scratches. However, the achieved removal rate of $\mathrm{GaN}$ by CMP was not sufficiently high to apply the production process as the $\mathrm{Ga}$ face of $\mathrm{GaN}$ is inert to almost all chemical solutions. ${ }^{(8)}$ Considering the insufficient development in the CMP for GaN substrate, dry etch is widely used as the final surface treatment for the GaN substrate as it is already commonly used for producing the mesa structure in nitride thin films in the device process of LEDs and LDs. ${ }^{(9-11)}$ Reactive ion etching (RIE), electron cyclotron resonance (ECR), and inductively coupled plasma (ICP) technology are used in this approach. The most important feature of plasma dry etching is the much faster etching rate of $\mathrm{GaN}$ than in the wet processes. ${ }^{(12-14)}$ However, in general, the plasma dry etching removes subsurface damage induced by the mechanical polishing but it does not remove the scratches since dry etching proceeds randomly without reference to a flat surface. Thus, the scratches produced by the mechanical processing before dry etching remain on the surface after dry etching. In addition to this, it has been reported that the plasma etching conditions for producing the mesa structure in nitride thin films in the device process strongly affect the degradation of the electrical performance of fabricated LEDs. ${ }^{(8,15,16)}$ This suggests that there is damage being introduced onto the surface of the GaN substrate by the plasma dry etching, which is the so-called "plasma-induced damage".

As described above, both CMP and dry etching seem to have advantages and disadvantages. However, there is no report dealing with their systematic comparison. Therefore, in this paper, we present for the first time a direct comparison of CMP and ICP dry etching surface treatment methods for GaN substrates. Both CMP with the colloidal silica slurry and ICP dry etching with $\mathrm{SiCl}_{4}$ are applied to a GaN substrate pretreated by mechanical polishing with a diamond abrasive. The advantages and disadvantages of both CMP and ICP dry etching surface treatment methods are summarized, and a separate discussion of the factors affecting the surface roughness, damage removal, and damage introduced during each process is conducted to give insight into a suitable surface treatment of the GaN substrate for epitaxy. In addition, we will present for the first time as well a clear evidence of the introduction of plasma-induced damage by applying the ICP dry etching to the CMP-finished GaN substrate. The possible reasons for the generation of plasma-induced damage to the GaN substrate by plasma dry etching are also discussed in detail. 


\section{Experimental Procedure}

\subsection{Diamond polishing for GaN substrate as a preprocessing for final surface treatment}

An as-lapped GaN substrate from a commercial source was used in this study. Prior to the final surface treatment with either CMP or dry etching, the GaN substrate was mechanically polished with a diamond abrasive in several steps using progressively smaller sized diamond abrasives. As the first step, a 2.0- $\mu \mathrm{m}$-diameter diamond abrasive (2.0 $\mu \mathrm{m}$ diamond abrasive) was used to remove the initial surface roughness. The polishing with the $2.0 \mu \mathrm{m}$ diamond abrasive was followed by the second diamond polishing with a $0.5-\mu \mathrm{m}$-diameter diamond abrasive $(0.5 \mu \mathrm{m}$ diamond abrasive $)$. Some of the GaN substrates polished with the $0.5 \mu \mathrm{m}$ diamond abrasive were subjected to the further polishing with a 0.25 - $\mu \mathrm{m}$-diameter diamond abrasive $(0.25 \mu \mathrm{m}$ diamond abrasive $)$ before the final surface treatment. Detailed conditions of the diamond polishing processes are given in Table 1.

\subsection{CMP treatment for GaN substrate}

After the diamond polishing, CMP was employed in the GaN substrate. A tabletop polisher with a 300-mm-diameter platen was used for CMP process. The typical CMP conditions are described elsewhere. ${ }^{(7)}$ Among the several candidates of the slurry for CMP, colloidal silica is the most popular and used in the actual industries for CMP of silicon, glass, and sapphire substrate. Therefore, a commercially available colloidal silica was selected as a slurry for CMP of the GaN substrate. The removal rate of GaN by CMP was $17 \mathrm{~nm} / \mathrm{h}$ under the typical CMP conditions. ${ }^{(7)}$

\subsection{ICP dry etching for GaN substrate}

Dry etching was also applied to the substrate pretreated by mechanical polishing with the diamond abrasive. Among the several dry-etching techniques, we employed ICP etching. This is because ICP etching can minimize damage while maintaining fast etching rates. In addition, ICP etching is generally believed to have several advantages in terms of scale-up for production, improved plasma uniformity over a wide area and low operation costs. ${ }^{(8)}$ A commercially available dry etcher, which is commonly used for the fabrication of the mesa structure for LEDs, was used for the dry etching of the GaN

Table 1

Conditions for preprocesses with diamond abrasive.

\begin{tabular}{llccc}
\hline & & 1st polishing & 2nd polishing & 3rd polishing \\
\hline Abrasive size & $(\mu \mathrm{m})$ & 2 & 0.5 & 0.25 \\
Applied pressure & $\left(\mathrm{kg} / \mathrm{cm}^{2}\right)$ & 0.1 & 0.1 & 0.1 \\
Platen rotation & $\left(\mathrm{min}^{-1}\right)$ & 50 & 50 & 50 \\
Platen size & $(\mathrm{mm})$ & 380 & 380 & 380 \\
\hline Platen material & & $\mathrm{Cu}$ & $\mathrm{Sn}$ & $\mathrm{Sn}$ \\
\hline
\end{tabular}


substrate. $\mathrm{SiCl}_{4}$ gas was used as the etching gas. Two different etching rates were applied to etch the GaN substrate by changing the bias power: 185 and $685 \mathrm{~nm} / \mathrm{min}$, which is a typical range of the etching rate used for producing the mesa structure of LEDs and LDs.

\subsection{Surface and subsurface evaluations after surface treatment}

The surface roughness was evaluated by optical microscopy (OM) and atomic force microscopy (AFM). Generally, mechanical polishing with diamond abrasives generates networks of dislocations at or near the surface region of the substrate. The dislocations related to surface defects such as scratches can be evaluated by regular surface analysis such as by OM and AFM. For the subsurface dislocations, however, we need a different approach to visualize their existence. In this work, the removal of subsurface damage induced by mechanical polishing is evaluated from the cathodoluminescence (CL) intensity and also visually understood by CL imaging. As dislocation areas act as nonradiative recombination sites, dislocations appear as dark areas in the CL image, leading to a decrease in the CL intensity. ${ }^{(17)}$ Therefore, CL evaluation is one powerful method for understanding the damage existing beneath the surface of GaN substrates. ${ }^{(7)}$ The CL was excited by accelerated electrons with the energy of $5 \mathrm{kV}$, corresponding to the maximum penetration depth of $0.22 \mu \mathrm{m}$. $^{(18)}$

\section{Results and Discussion}

\subsection{CMP treatment for GaN substrate}

The surface conditions after the mechanical polishing with the diamond abrasive as a preprocessing for the final surface treatment were evaluated by OM and AFM. The $\mathrm{OM}$ image of the GaN substrate mechanically polished with a $0.5 \mu \mathrm{m}$ diamond abrasive is shown in Fig. 1. AFM images of the GaN substrate mechanically polished with 0.5 or $0.25 \mu \mathrm{m}$ diamond abrasive are shown in Figs. 2(a) and 2(b), respectively. Numerous scratches made by the diamond abrasive are observed in the OM and AFM images. The

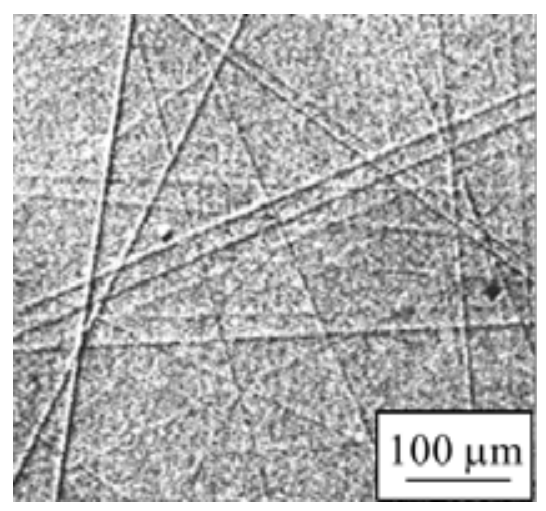

Fig. 1. OM image of $\mathrm{GaN}$ surface processed with a $0.5 \mu \mathrm{m}$ diamond abrasive. 

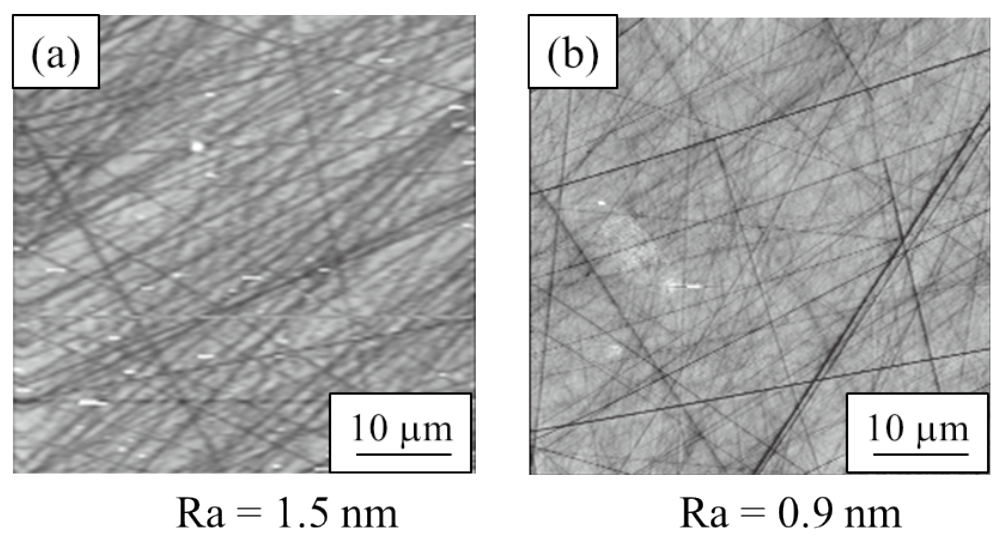

Fig. 2. AFM image of GaN surface processed with a (a) 0.5 or (b) $0.25 \mu \mathrm{m}$ diamond abrasive.

surface roughnesses after the 0.5 and $0.25 \mu \mathrm{m}$ diamond polishing were 1.5 and $0.9 \mathrm{~nm}$, respectively. Thus, the smaller diamond abrasive produces a smoother GaN surface.

Then, CMP was conducted for the substrates preprocessed by diamond polishing. The removal of subsurface mechanical damage during CMP was evaluated by CL. Figures 3(a)-3(c) show the CL images of the GaN surface after diamond polishing with the $0.5 \mu \mathrm{m}$ diamond abrasive, at an intermediate stage of CMP, and after CMP. Just after the diamond polishing, the CL image is dominated by black lines as shown in Fig. 3(a). The black lines correspond to the subsurface damage induced by the mechanical polishing as the damaged areas act as nonradiative recombination sites. It can be seen that the number of black lines decreases with increasing CMP process time. In the case where the GaN surface was preprocessed with the $0.5 \mu \mathrm{m}$ diamond abrasive, $150 \mathrm{~h}$ of CMP was required to obtain a damage-free surface. As Fig. 3(c) shows no black line, it indicates that CMP achieves a complete removal of subsurface damage induced by the mechanical polishing. In addition, after $150 \mathrm{~h}$ of CMP, a hexagonal morphology that corresponds to the crystalline structure of GaN is clearly observed, as shown in Fig. 3(c).

In the case where the GaN surface was polished with the $0.25 \mu \mathrm{m}$ diamond abrasive, the required time for CMP was reduced from 150 to $105 \mathrm{~h}$. The subsurface damage depths induced by the 0.5 and $0.25 \mu \mathrm{m}$ diamond abrasives can be estimated to be around 2.5 and $1.7 \mu \mathrm{m}$, respectively, considering the required time for CMP and the removal rate. We note that there was no significant difference in the surface quality after CMP between the GaN substrate preprocessed with the 0.5 and $0.25 \mu \mathrm{m}$ diamond abrasives. Therefore, the size of the diamond abrasive simply contributes to the shortening of the CMP time by reducing the depth of subsurface damage induced by mechanical polishing.

AFM images after $150 \mathrm{~h}$ of CMP are shown in Fig. 4, exhibiting the scratch-free surface. A crystal-oriented surface morphology is clearly observed in Fig. 4(a). The surface roughnesses were 0.3 and $0.2 \mathrm{~nm}$ over $50 \times 50$ and $5 \times 5 \mu \mathrm{m}^{2}$ areas, respectively. In the $5 \times 5 \mu \mathrm{m}^{2}$ area AFM image (Fig. 4(b)), we see crystal-oriented atomic step structures due to crystal misorientation. As a result, it is concluded that an atomically 

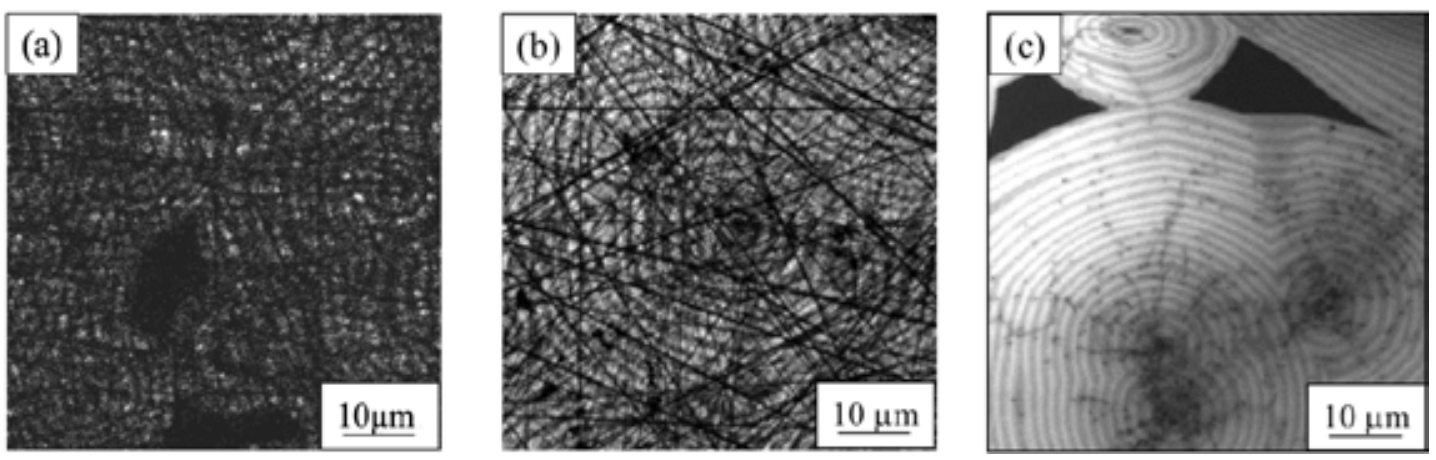

Fig. 3. CL images of the GaN substrate (a) before, (b) at an intermediate stage of CMP (70 h of CMP), and (c) after CMP (150 h of CMP). Preprocessing of CMP is mechanical polishing with a 0.5 $\mu \mathrm{m}$ diamond abrasive.
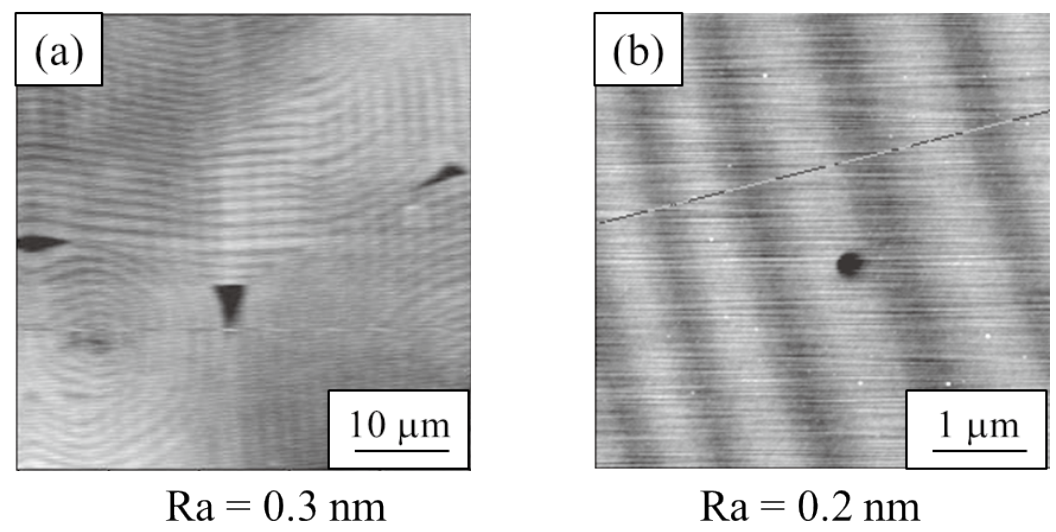

Fig. 4. AFM image of GaN surface after CMP over (a) $50 \times 50$ and (b) $5 \times 5 \mu^{2}$ areas. Preprocessing of CMP is mechanical polishing with a $0.5 \mu \mathrm{m}$ diamond abrasive.

flat surface without subsurface damage is produced by CMP with colloidal silica slurry. However, the extremely low removal rate, $17 \mathrm{~nm} / \mathrm{h}$, is a serious issue for CMP of the GaN substrate, causing the necessity of over $100 \mathrm{~h}$ of CMP.

\subsection{ICP dry etching for GaN substrate}

As mentioned above, it was found that the thickness needed to remove the subsurface damage induced by mechanical polishing is around $2.5 \mu \mathrm{m}$ for the GaN substrate preprocessed with the $0.5 \mu \mathrm{m}$ diamond abrasive. Therefore, at least $2.5 \mu \mathrm{m}$ of the GaN substrate was etched from the surface by ICP dry etching using $\mathrm{SiCl}_{4}$ with a $185 \mathrm{~nm} /$ min etching rate. In the dry etching, the initial scratches produced by the mechanical 
polishing were emphasized as seen in the comparison between Figs. 1 and 5(a), which are the OM images of the surface before and after ICP dry etching, respectively. Thus, it is indicated that reduction of the scratch width and depth as much as possible is necessary for the preprocessing of dry etching.

To investigate the effect of the smaller diamond abrasive for the preprocessing on the surface quality of the GaN substrate after dry etching, mechanical polishing with a 0.25 $\mu \mathrm{m}$ diamond abrasive was applied after that with a $0.5 \mu \mathrm{m}$ diamond abrasive, and then, the substrate was subsequently processed by dry etching using $\mathrm{SiCl}_{4}$ with a $185 \mathrm{~nm} / \mathrm{min}$ etching rate. As the subsurface damage thickness that needed to be removed was 1.7 $\mu \mathrm{m}$ in this case based on the CMP experiments, at least $1.7 \mu \mathrm{m}$ of the GaN substrate was etched from the surface by the dry etching. An OM image of the GaN substrate after the dry etching is shown in Fig. 5(b). By preprocessing with the $0.25 \mu \mathrm{m}$ diamond abrasive, much improved surface quality and less-damaged surface were achieved after the dry etching. The detailed surface roughness was evaluated by AFM as shown in Fig. 6. As compared with the surface before dry etching (Fig. 2(b)), the surface roughness was degraded from 0.9 to $1.9 \mathrm{~nm}$. Therefore, it is suggested that the dry etching cannot produce an atomically flat surface.

Figure 7 shows the CL images of GaN after the dry etching. While visible scratches still remain on the surface after dry etching of the GaN substrate as seen in the surface observation by OM and AFM, it is found that dark lines corresponding to the mechanical damage induced by mechanical polishing were completely removed by ICP dry etching regardless of the diamond abrasive size used in the preprocessing (see Fig. 3 for reference). However, as seen in the comparison between Figs. 7(a) and 7(b), we see a large difference in the clearness and intensity of the CL emission images between the surfaces finished by ICP dry etching with $0.5 \mu \mathrm{m}$ diamond abrasive preprocessing and that with $0.25 \mu \mathrm{m}$ diamond abrasive preprocessing. The depth of the damaged layer produced by mechanical polishing is known from the CMP experiments, and we
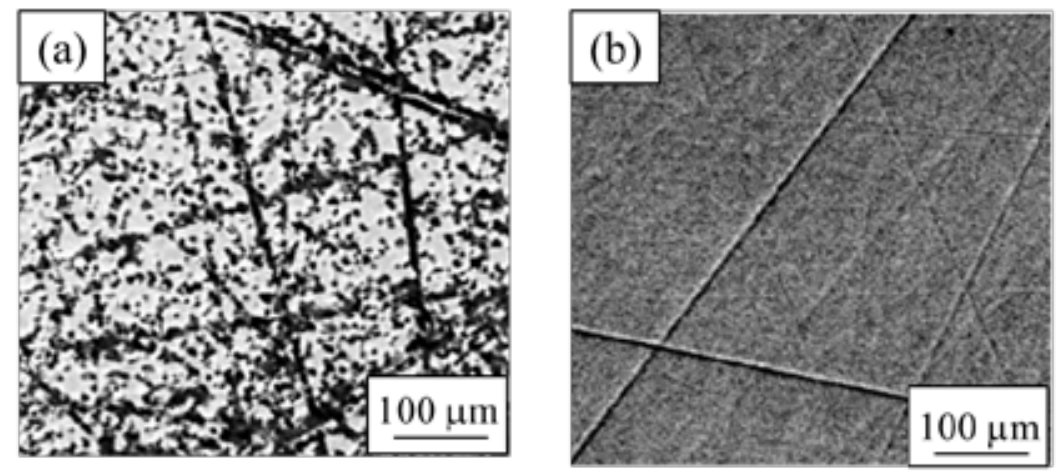

Fig. 5. OM image of GaN surface after dry etching. Preprocessing of dry etching was mechanical polishing with a (a) 0.5 or (b) $0.25 \mu \mathrm{m}$ diamond abrasive. 


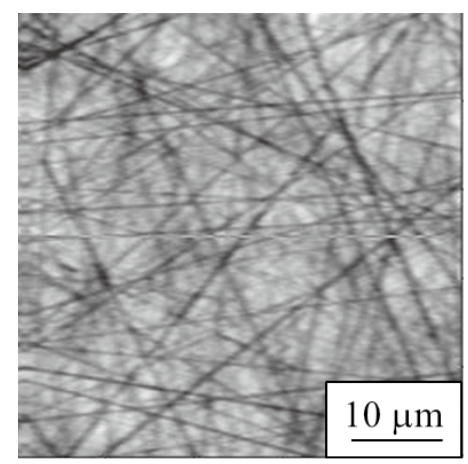

$$
\mathrm{Ra}=1.9 \mathrm{~nm}
$$

Fig. 6. AFM image of GaN surface after dry etching. Preprocessing of dry etching was mechanical polishing with a $0.25 \mu \mathrm{m}$ diamond abrasive.
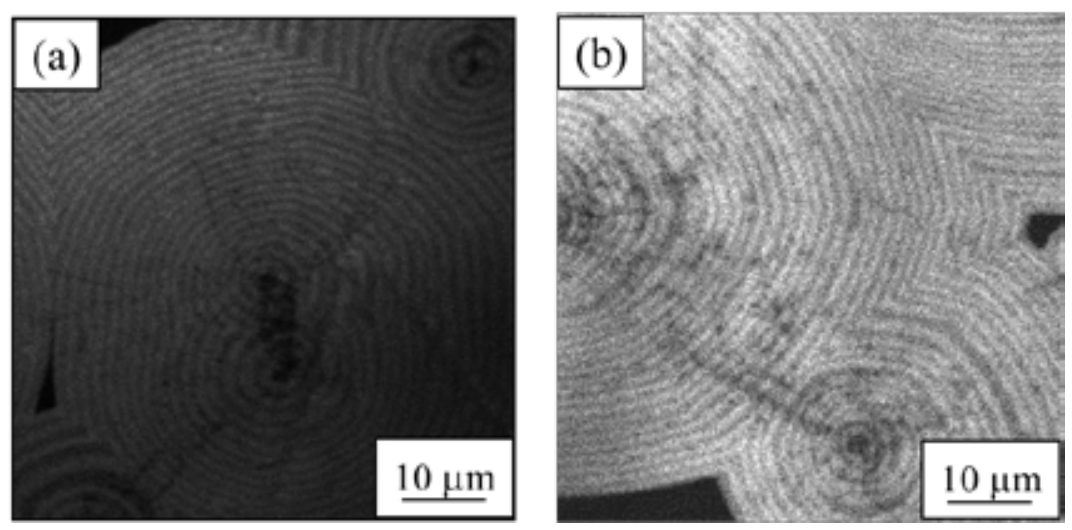

Fig. 7. CL images of the GaN substrate after dry etching. Preprocessing of dry etching is mechanical polishing with a (a) 0.5 or (b) $0.25 \mu \mathrm{m}$ diamond abrasive.

removed it completely by ICP dry etching. Therefore, the lower CL intensity for the dryetched GaN substrate suggests that a plasma-induced damage is introduced during the ICP dry etching. A longer plasma irradiation time seems to lead to an accumulation of the plasma-induced damage.

As a result, it is confirmed that subsurface damage removal induced by mechanical polishing can be achieved by ICP dry etching with a remarkably high etching rate. However, since the dry etching proceeds randomly without reference to a flat surface, the surface scratches produced by mechanical polishing are not removed by the dry 
etching. Thus, it is thought to be important for the pretreatment for dry etching to reduce the depth of the scratches as much as possible. It was also suggested that the ICP dry etching newly introduced subsurface damage, namely, plasma-induced damage.

\subsection{Evidence of introduction of plasma-induced damage by ICP dry etching}

By comparing the two surface treatments, CMP and ICP dry etching, their advantages and disadvantages were revealed. However, the discussion on the subsurface damage and plasma-induced damage, and their relationship with CL intensity between the treatments has not been sufficiently done yet. Therefore, to directly discuss them, the CMP-finished GaN substrate was etched by ICP dry etching using $\mathrm{SiCl}_{4}$ with two different etching rates: 185 and $685 \mathrm{~nm} / \mathrm{min}$. The etched depth was $0.5 \mu \mathrm{m}$ for both etching rates.

Figure 8 shows the AFM image after dry etching at a rate of $185 \mathrm{~nm} / \mathrm{min}$. The crystal-oriented surface features observed after CMP (Fig. 4) disappeared after dry etching. The substrate threading dislocations are observed to have been heavily etched and holes were formed on the surface. The surface roughness increased after dry etching from 0.3 to $0.9 \mathrm{~nm}$. Figures 9(a) and 9(b) show the CL images after ICP dry etching at the rates of 185 and $685 \mathrm{~mm} / \mathrm{min}$, respectively. The clarity of the CL image diminishes after the dry etching (see Fig. 3(c) for reference CL image of CMP-finished GaN substrate). This is also detailed in Fig. 10, showing the CL spectrum from these samples and a typical CMP-finished GaN substrate as a reference. The CL intensity is seen to decrease with increasing ICP etching rate. These results, therefore, clearly suggest that ICP dry etching introduces subsurface damage, namely, this is a clear evidence of plasma-induced damage to the GaN substrate. It can also be concluded that a higher ICP dry etching rate leads to a more serious degradation of the GaN substrate surface quality.

The possible reasons for the degradation of the CL intensity and its relationship with the plasma-induced damage are worth discussing. There are some related reports on the

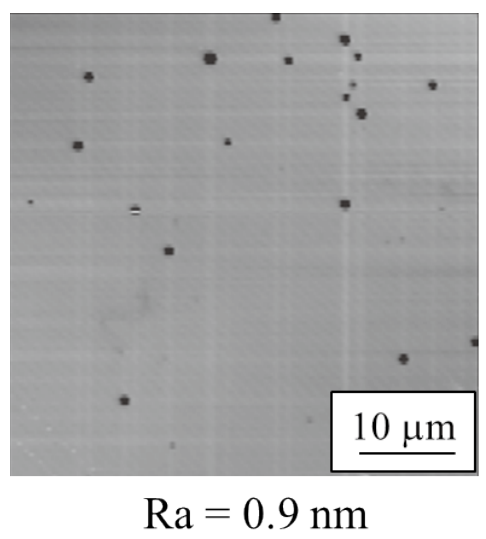

Fig. 8 AFM image of GaN surface dry-etched at a $185 \mathrm{~nm} / \mathrm{min}$ etch rate. Image size is $50 \times 50$ $\mu \mathrm{m}^{2}$. 

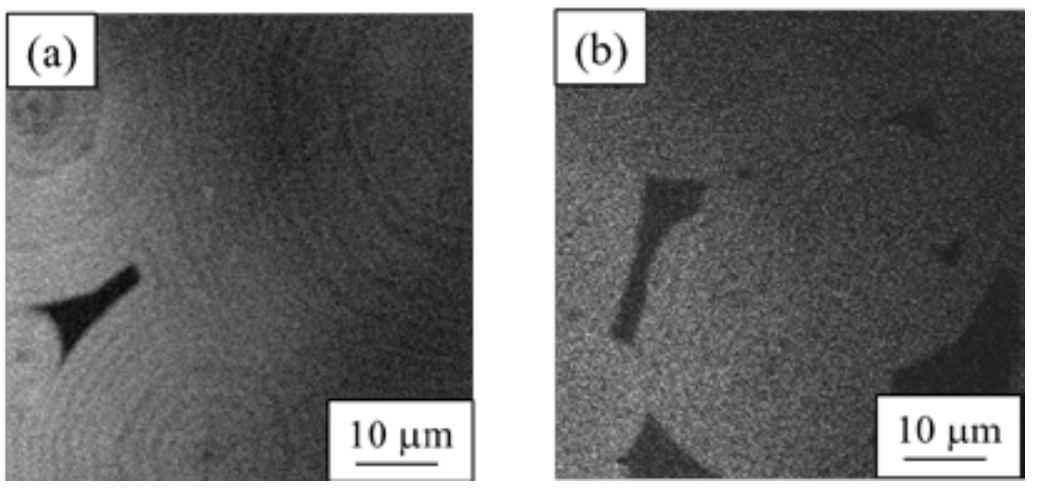

Fig. 9. CL image of GaN substrate dry-etched at a (a) 185 or (b) $685 \mathrm{~nm} / \mathrm{min}$ etch rate. Preprocessing of dry etching is CMP.

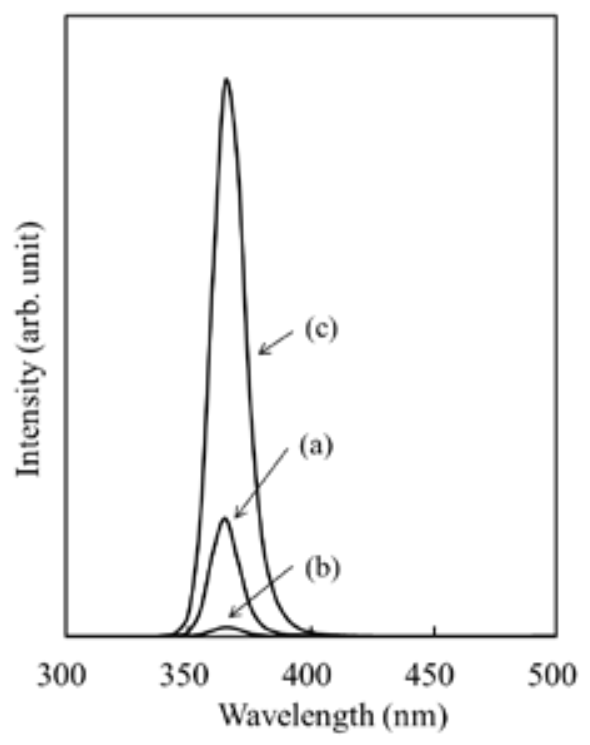

Fig. 10. CL spectrum from GaN surface after dry etching at (a) 185 and (b) $685 \mathrm{~nm} / \mathrm{min}$ etch rates. Preprocessing of dry etching is CMP. The CL spectrum from as-CMP GaN surface is also shown in (c) as a reference.

deterioration of the photoluminescence (PL) intensity of GaN thin films after dry etching in the mesa structure production for LEDs, and the following three possible reasons have been suggested: (1) formation of $\mathrm{Ga}-\mathrm{O}$ bonds at the $\mathrm{GaN}$ surface, ${ }^{(16,19)}(2)$ adsorption of $\mathrm{Cl}$ atoms on and near the surface, ${ }^{(15,20)}$ and (3) destruction of the GaN crystal surface. ${ }^{(21)}$ 
To understand the observed deterioration in the CL intensity due to ICP dry etching, these three factors should be discussed.

(1) Formation of $\mathrm{Ga}-\mathrm{O}$ bonds at the GaN surface: Han et al. ${ }^{(16)}$ reported evidence of $\mathrm{Ga}$ $-\mathrm{O}$ formation on the $\mathrm{Cl}_{2} / \mathrm{Ar}$ ICP-etched $\mathrm{GaN}$ thin film surface. The oxidation may occur when the GaN film surface was exposed to the air environment after ICP dry etching. It has been reported that oxygen bonded to GaN serves as a nonradiative recombination site. ${ }^{(19)}$ On the other hand, it has also been reported that $\mathrm{GaN}$ is polished by the surface oxidation mechanism of forming $\mathrm{Ga}_{2} \mathrm{O}_{3}$ followed by the dissolution of $\mathrm{Ga}_{2} \mathrm{O}_{3}$ into a chemical solution. ${ }^{(22-24)}$ Therefore, the CMP-finished $\mathrm{GaN}$ surface already forms $\mathrm{Ga}_{2} \mathrm{O}_{3} \cdot{ }^{(25,26)}$ Considering that the best CL intensity was obtained from the GaN surface finished by $\mathrm{CMP}$, the formation of $\mathrm{Ga}-\mathrm{O}$ bonds at the GaN surface by ICP dry etching is not considered to be a reason for the degradation of the CL intensity.

(2) Adsorption of $\mathrm{Cl}$ atoms on and near the surface: $\mathrm{As} \mathrm{Cl}$ shows strong electronegativity, it may affect the electrical conditions of the surface atoms and thus affect electron behavior during CL measurements. Therefore, measurement of the $\mathrm{Cl}$ contamination on and near the surface by total X-ray reflection fluorescence (TXRF) and removal of the surface-adsorbed $\mathrm{Cl}$ by cleaning with a wet acid solution (a mixture of $\mathrm{H}_{2} \mathrm{SO}_{4}$ and $\mathrm{H}_{2} \mathrm{O}_{2}$ ) for $10 \mathrm{~min}$ at $100^{\circ} \mathrm{C}$ were conducted using the $\mathrm{GaN}$ substrate finished with CMP and subsequent ICP dry etching. Figure 11 shows the number of surface $\mathrm{Cl}$ atoms measured by TXRF. There is a difference of two orders of magnitude in the number of adsorbed $\mathrm{Cl}$ atoms between the CMP-finished and dry-etched GaN. After cleaning, some adsorbed $\mathrm{Cl}$ atoms are removed, and the number of $\mathrm{Cl}$ atoms drops to the same level as that of the CMP-finished GaN substrate. Figure 12 shows

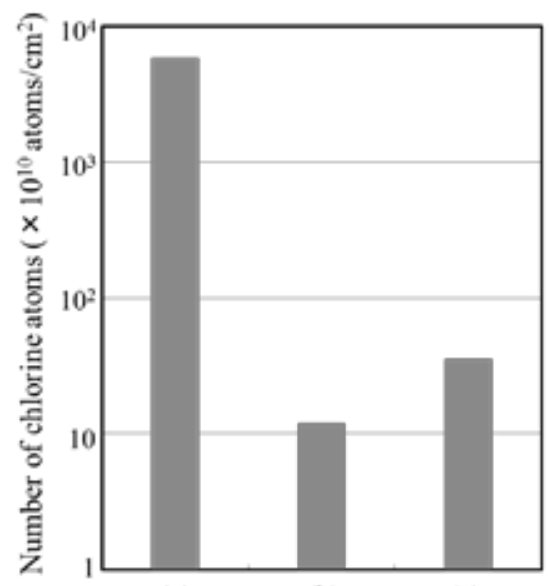

(a) (b)

(c)

Fig. 11. Comparison of the number of chlorine atoms measured by TXRF for surface of (a) as-dry etched, (b) dry etched and then cleaned with wet acid, and (c) as-CMP-finished GaN substrate. 


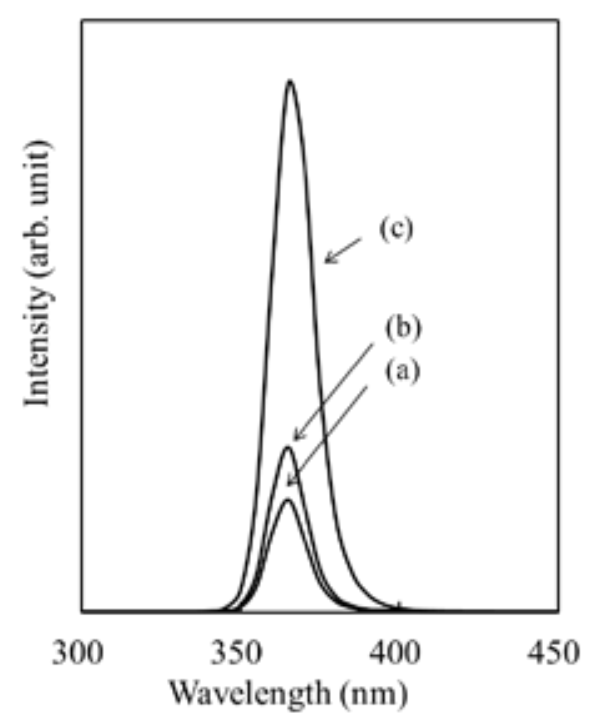

Fig. 12. CL spectrum from surface of (a) as-dry etched, (b) dry etched and then cleaned with wet acid, and (c) as-CMP-finished GaN substrate.

the CL spectra of the GaN substrate treated by ICP dry etching before and after cleaning together with the CMP-finished surface for reference. The CL intensity increased slightly after cleaning. However, there is still a large difference between the CMP-finished and cleaned $\mathrm{GaN}$ surfaces. Therefore, $\mathrm{Cl}$ adsorption on and near the $\mathrm{GaN}$ surface is not the main cause of the deterioration in the CL intensity.

(3) Destruction of the GaN crystal surface: This is likely to be the most reasonable explanation for the lower CL intensity since reasons (1) and (2) have been rejected. Jeong et al. ${ }^{(27)}$ reported that the plasma-induced damage on the $\mathrm{N}$ face of $\mathrm{GaN}$ can be removed by $\mathrm{KOH}$ etching with an etch depth of $\sim 500 \mathrm{~nm}$. They also reported that the etching rate of the $\mathrm{N}$ face of $\mathrm{GaN}$ by $\mathrm{KOH}$ etching is markedly affected by the previous ICP etching conditions. These results may indicate that the plasma-induced damage is created inside the crystal as subsurface damaged layers. In addition, Waki et al.(28) have reported the reaction scheme for Cl-based ICP dry etching, and the etching reaction is reported to proceed with the following steps: neutral $\mathrm{Cl}$ adsorption, reaction of $\mathrm{Cl}$ with $\mathrm{GaN}$ to form etch products, and ion bombardment of the surface to desorb the etch products. Therefore, the ion bombardment in ICP dry etching is considered to mechanically affect the GaN surface and to create nonradiative recombination centers as, presumably, a network of point defects. Consequently, the related CL intensity degradation was observed for the GaN substrate after ICP dry etching.

\subsection{Summary}

Before providing the conclusions, here, we summarize the advantages, disadvantages, and effect of preprocessing on the surface quality for CMP and ICP dry etching. 
(1) Advantages of CMP: CMP produces an atomically flat surface and complete absence of subsurface damage simultaneously.

(2) Disadvantage of CMP: the removal rate is insufficiently high under typical CMP conditions.

(3) Effect of preprocessing for CMP: the use of mechanical polishing with the smaller diamond abrasive contributes to the reduction of the required CMP time for producing the complete damage-free surface but does not affect the CMP surface quality.

(4) Advantage of ICP dry etching: the removal of subsurface damage induced by mechanical polishing is achieved with a remarkably high etching rate.

(5) Disadvantages of ICP dry etching: no planarization effect can be obtained (scratches remain on the surface after ICP dry etching), and introduction of a network of point defects as plasma-induced damage occurs.

(6) Effect of preprocessing for ICP dry etching: producing the smoother surface and shallower subsurface damage by mechanical polishing with the smaller diamond abrasive contribute to the better surface roughness and reduced plasma-induced damage.

Finally, as future tasks, CMP requires the marked improvement in the removal rate. On the other hand, ICP dry etching requires a suitable preprocessing to minimize the surface roughness and reduced introduction of plasma-induced damage to suppress the network of point defects. By resolving the issues revealed in this study, surface finishing technique will be established for GaN substrate manufacturing in mass-production scale, which will lead to an acceleration of the use of the GaN substrate for LEDs and LDs, and the realization of next-generation high-frequency, high-power devices with GaN substrate.

\section{Conclusions}

The first direct comparison of CMP and dry etching surface treatment methods for $\mathrm{GaN}$ substrates was presented, and the advantages and disadvantages of the surface treatment for $\mathrm{GaN}$ substrate are experimentally compared to understand the current issues for these techniques and to provide insight for the development of a suitable surface treatment for the GaN substrate. CMP finishing of the GaN substrate exhibits a perfect surface free of scratches and damage. However, the extremely low removal rate in CMP is found to be a critical issue. On the other hand, ICP dry etching exhibits a remarkably high removal rate and removal of the subsurface damage induced by mechanical polishing. However, ICP etching does not remove the surface scratches produced by the mechanical process. In addition, plasma-induced damage as a result of the ICP dry etching is observed clearly in the deterioration of the CL intensity after ICP dry etching of the CMP-finished GaN substrate. The deterioration of the CL intensity is considered to be caused by the creation of nonradiative recombination sites that are presumably a network of point defects originating from the mechanical effects of dry etching such as ion bombardment. Finally, the current issues to be resolved for CMP and ICP dry etching have been understood clearly toward the development of a suitable surface treatment for GaN substrate. These are (i) a marked improvement in the removal rate of CMP, (ii) a suitable preprocessing for ICP dry etching, and (iii) reduced introduction of plasma-induced damage. 


\section{References}

1 S. Krukowski, I. Grezegory, M. Bockowski, B. Lucznik, T. Suski, G. Nowak, J. Borysiuk, M. Wroblewski, M. Leszczynski, P. Perlin, S. Porowski and J. L. Weyher: Int. J. Mater. Product Technol. 22 (2005) 226.

2 K. Motoki, T. Okahisa, R. Hirota, S. Nakahata, K. Uematsu and N. Matsumoto: J. Cryst. Growth 305 (2007) 377.

3 T. Yoshida, Y. Oshima, T. Eri, K. Ideda, S. Yamamoto, K. Watanabe, M. Shibata and T. Mishima: J. Cryst. Growth 310 (2008) 5.

4 T. Hashimoto, F. Wu, J. S. Speck and S. Nakamura: Nat. Mater. 6 (2007) 568.

5 F. Kawamura, T. Iwahashi, K. Omae, M. Morishita, M. Yoshimura, Y. Mori and T. Sasaki: Jpn. J. Appl. Phys. 42 (2003) L4.

6 Y. Isobe, D. Iida, T. Sakakibara, M. Iwaya, T. Takeuchi, S. Kamiyama, I. Akasaki, H. Amano, M. Imade, Y. Kitaoka and Y. Mori: Phys. Status Solidi C 8 (2011) 2095.

7 H. Aida, H. Takeda, K. Koyama, H. Katakura, K. Sunakawa and T. Doi: J. Electrochem. Soc. 158 (2011) H1206.

8 S. J. Peartona, J. C. Zolper, R. J. Shul and F. Ren: J. Appl. Phys. 86 (1999) 1.

9 P. Gillis, D. A. Choutov, P. A. Steiner, J. D. Piper, J. H. Crouch, P. M. Dove and K. P. Martin: Appl. Phys. Lett. 66 (1995) 2475.

10 I. Adesida, A. Mahajan, E. Andideh, M. Asif Khan, D. T. Olsen and J. N. Kuznia: Appl. Phys. Lett. 63 (1993) 2777.

11 I. Adesida, A. T. Ping, C. Youtsey, T. Dow, M. Asif Khan, D. T. Olson and J. N. Kuznia: Appl. Phys. Lett. 65 (1994) 889.

12 J. W. Lee, J. Hong, J. D. MacKenzie, C. R. Abernathy, S. J. Pearton, F. Ren and P. F. Sciortino: J. Electron. Mater. 26 (1997) 290.

13 C. B. Vartuli, S. J. Pearton, J. W. Lee, J. Hong, J. D. MacKenzie, C. R. Abernathy and R. J. Shul: Appl. Phys. Lett. 69 (1996) 1426.

14 R. J. Shul, A. J. Howard, S. J. Pearton, C. R. Abernathy, C. B. Vartuli, P. A. Barnes and M. J. Bozack: J. Vac. Sci. Technol. B 13 (1995) 2016.

15 H.-S. Kim, G.-Y. Yeom, J.-W. Lee and T.-I. Kim: Thin Solid Films 341 (1999) 180.

16 Y.-J. Han, S. Xue, W.-P. Guo, C.-Z. Sun, Z.-B. Hao and Y. Luo: Jpn. J. Appl. Phys. 42 (2003) 6409.

17 D. Hanser, M. Tutor, E. Preble, M. Williams, X. Xu, D. Tsvetkov and L. Lin: J. Cryst. Growth 305 (2007) 372.

18 J. Murata, A. Kubota, K. Yagi, Y. Sano, H. Hara, K. Arima, T. Okamoto, H. Mimura and K. Yamauchi: Mater Sci. Forum 600 (2009) 815.

19 H. W. Choi, S. J. Chua, A. Ramam, J. S. Pan and A. T. S. Wee: Appl. Phys. Lett. 77 (2000) 1795.

20 H. S. Kim, Y. H. Lee, G. Y. Yeom, J. W. Lee and T.-I. Kim: Mater. Sci. Eng. B 50 (1997) 82.

21 K. Remashan, S. J. Chua, A. Ramam, S. Prakash and W. Liu: Semicond. Sci. Technol. 15 (2000) 386.

22 S. Sadakuni, J. Murata, K. Yagi, Y. Sano, K. Arima, A. Hattori, T. Okamoto and K. Yamauchi: Mater. Sci. Forum 645 (2010) 795.

23 K. Yagi, J. Murata, A. Kubota, Y. Sano, H. Hara, K. Arima, T. Okamoto, H. Mimura and K. Yamauchi: Jpn. J. Appl. Phys. 47 (2008) 104.

24 K. Yagi, J. Murata, A. Kubota, Y. Sano, H. Hara, T. Okamoto, K. Arima, H. Mimura and K. Yamauchi: Surf. Interface Analysis 40 (2008) 998.

25 N. Shiozaki, T. Sato and T. Hashizume: Jpn. J. Appl. Phys. 46 (2007) 1471.

26 A. N. Hattori, K. Endo, K. Hattori and H. Daimon: Appl. Surf. Sci. 256 (2010) 4745. 
27 T. Jeong, H. H. Lee, K. H. Kim, S. R. Jeon, S. J. Lee, S. H. Lee, J. H. Baek and J. K. Lee: J. Korean Phys. Soc. 55 (2009) 1140.

28 I. Waki, M. Iza, J. S. Speck, S. P. Denbaars and S. Nakamura: Jpn. J. Appl. Phys. 45 (2006) 720.

\section{About the Authors}

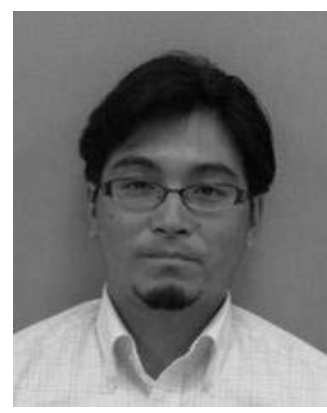

Hideo Aida is currently the president of NJC Institute of Technology of Namiki Precision Jewel Co. Ltd. His research covers bulk crystal growth, ultraprecision processing, and thin-film epitaxy for functional optoelectronics materials such as sapphire, $\mathrm{GaN}, \mathrm{SiC}$, and diamond. $\mathrm{He}$ is the co-organizer of the Research Committee on Ultraprecision Processing for Nitride Semiconductor Devices of JSME, and a member of the Planarization CMP Committee of JSPE, Committee on FutureOriented Machining of JSPE, and other research associations.

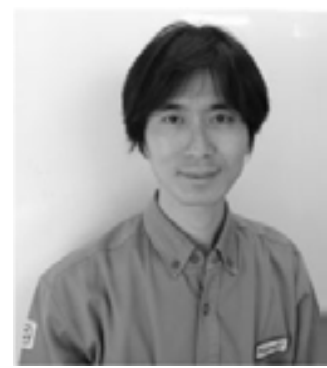

Hidetoshi Takeda is the chief of the Process Development section of NJC Institute of Technology. His research covers ultraprecision laser processing for transparent materials such as silica glass, sapphire and diamond. Furthermore, he is specialized in clarifying the polishing mechanism and development of high-speed CMP technology for nitride single crystals.

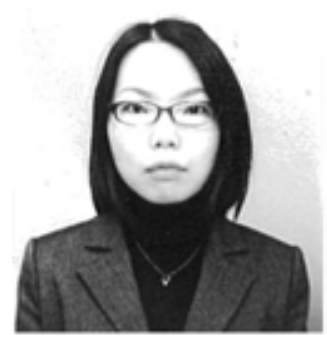

Natsuko Aota is the chief of the R \& D marketing section of NJC Institute of Technology. She has been working on the microfabrication, and ultraprecision processing of lightemitting diode materials such as sapphire, GaN, and $\mathrm{ZnO}$. She is a member of the Research Committee on Ultraprecision Processing for Nitride Semiconductor Devices of JSME.

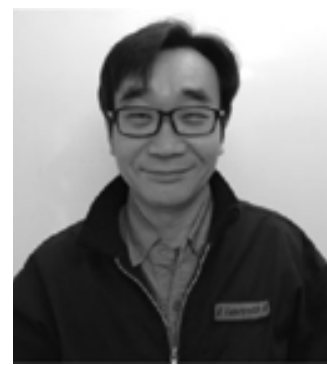

Seong-Woo Kim is a research engineer of the Crystal Growth Section of NJC Institute of Technology. He is engaged in research on the thin/thick GaN growth on sapphire substrate using MOCVD and HVPE, and also mainly engaged in the study of GaN polishing. 


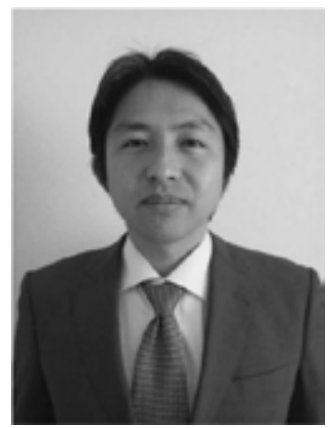

Koji Koyama is the manager of the detached office of NJC Institute of Technology in the Akita factory of Namiki Precision Jewel Co., Ltd. He investigates crystal growth and ultraprecision polishing technology of sapphire, GaN, and diamond. Micro- and nanoprocessing of diamond is also his specialized field. He is a member of the Planarization CMP Committee of JSPE and Japan New Diamond Forum. 